\title{
Celebrating 90 years of Peking University School of Life Sciences (1925-2015)
}

\author{
XU ZhiHong \& ZHU ZuoYan \\ School of Life Sciences, Peking University, Beijing 100871, China \\ Citation: $\quad$ Xu ZH, Zhu ZY. Celebrating 90 years of Peking University School of Life Sciences (1925-2015). Sci China Life Sci, 2015, 58: 1055-1056, \\ doi: $10.1007 / \mathrm{s} 11427-015-4963-8$
}

The Department of Biology at Peking University was established in 1925, with Mr. Tan XiHong as its inaugural department head. In 1993, the department was renamed the School of Life Sciences. During the past 90 years, a steady stream of students has enrolled in the department in order to explore the secrets of life and to dedicate themselves to the advancement of society.

The School of Life Sciences' 90 years of history is both a history of its development and a history of the struggles of the school's dreamers and relentless explorers. In 1931, Hao JingSheng, Shi YuanGao, and Zhang FengYing were the first three graduates of the department. They pursued the goal of "reviving China's biological discipline," and devoted themselves to laying the groundwork of modern botany, zoology, and pharmacology, thus joining the ranks of early planners and founders of biology in China.

Amidst the upheaval of the Anti-Japanese War (1937-1945), members of Biology and other faculties in Peking University united with those of Tsinghua University and Nankai University to relocate thousands of miles southwards, where they created the National Southwest Associated University. Under extremely dire conditions, the university retained a resolute and unwavering spirit and strongly adhered to the concept of "uninterrupted schooling and the nurturing of talent." Despite retreating to a remote corner of China, the school only focused on serving its country. Many of the teachers and students subsequently advanced to become the backbone of the teaching staff at Peking University's Department of Biology.

email: xuzh@pku.edu.cn; zhuzy@pku.edu.cn
Both of us joined the Department of Biology of Peking University in 1959: Xu ZhiHong as a student of botany and Zhu ZuoYan as a student of zoology. Six years of undergraduate studies transformed us from young students passionate about nature and biology into members of China's well-known center of biology. It has been 50 years since our class graduated. If the persistent explorations by members of Peking University's School of Life Sciences in the 1930s and 1940s reflected one aspect of the modern-history of the School, the students like us who graduated after the founding of the People's Republic of China in 1949 might reflect a different side of the story. As a result, we can apply our personal experiences to accompany the story of the growth of the new country of China: endeavor, perseverance, sustainable excellence, and endurance.

Members of Peking University's School of Life Sciences are people who are pursuing their dreams. The best representation of the realization of such dreams is that the teachers and students of the Department (together with those of the Department of Chemistry) collaborated on a renowned work for synthesizing the protein bovine insulin. Members of the School of Life Sciences are also people who hold on to their beliefs. Even during the three years of hardships (1959-1961), suffering extreme shortages of materials, food, and electricity, the joy of teaching and learning did not waiver! Every time we opened the coarse, yellow, mimeographed lecture handouts that had been written and engraved by our teachers, we became emotional. During the Cultural Revolution, the Department of Biology was forced to suspend classes for four years. After classes resumed, under extremely difficult conditions, life scientists still dis- 
played extraordinary perseverance and adhered to their pursuit of scientific truths.

Another thing that the School should take pride is implementing the CUSBEA (China United States Biochemistry Examination and Application) Program of the Education Ministry from 1982 to 1989 . Through this Program, a total of 422 highly competitive Ph.D. students were selected and placed in over 90 universities in the US. This program was initiated by Prof. Wu Ray of Cornell University on the US side and managed on the China side mainly by Prof. Gu XiaoCheng of the then Department of Biology, Peking University. This group of students (including three elected members of the US National Academy of Sciences, one elected member of the Chinese Academy of Sciences and a dozen or so HHMI investigators) are becoming leaders in biological science education and research within China and worldwide.

In the face of rapid changes in life sciences, students from Peking University have managed to make great achievements in domestic and international academic circles. Numerous students from the Peking University School of Life Sciences have been elected as members of the Chi- nese Academy of Sciences. Many outstanding individuals have also emerged from our alumni who have studied abroad, including three recently elected members of the United States National Academy of Sciences, Drs. Chen XueMei, Deng XingWang and Wu Hao, all of whom contributed an article for this special issue. And many have been appointed as investigators of Howard Hughes Medical Institute, such as Drs. Chen XueMei, Han Min Jin YiShi and Yu HongTao (who was a graduate of the Peking University Department of Chemistry), among the contributing authors of this special issue. There are also an increasing number of life sciences students who have studied abroad and have since decided to return to China after completing their studies or to serve our country in different ways.

Two sentences are carved on the newly erected Alumni Wall in the School of Life Sciences: "Forging ahead on the waves of ninety years, tirelessly cultivating talent for a century." We hope that the Peking University School of Life Sciences will use its ninetieth anniversary as a golden opportunity to stride towards another century of brilliant development!

\section{Biographical Sketch}

Xu ZhiHong, a plant biologist and an elected academician of the Chinese Academy of Sciences (1997) and the Third World Academy of Sciences (1995), graduated from Department of Biology, Peking University in 1965. He is professor of the Peking University School of Life Sciences and the Shanghai Institute of Plant Physiology and Ecology, Chinese Academy of Sciences. He is currently the President of the China National Committee of Man and Biosphere, UNESCO, and a member of

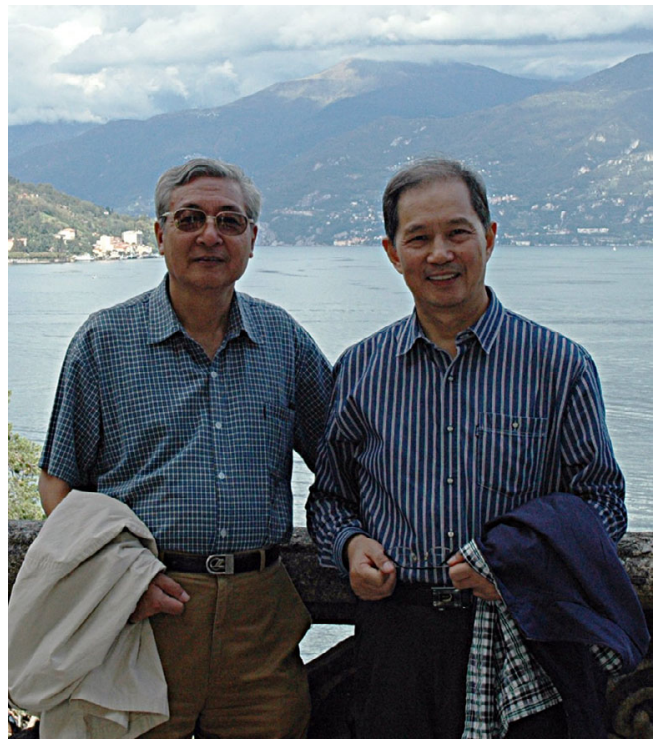

Xu ZhiHong (left) and Zhu ZuoYan (right) the National Consultative Committee, Ministry of Education, China. He served as the Director of the Shanghai Institute of Plant Physiology (1991-1994), Vice President of the Chinese Academy of Sciences from 1992 to 2002, and the President of Peking University from 1999 to 2008. His research interests include plant hormone and development, plant cell culture and agricultural biotechnology.

Zhu ZuoYan, a geneticist and an elected academician of the Chinese Academy of Sciences (1997), graduated from Department of Biology, Peking University in 1965. He later joined the Institute of Hydrobiology, Chinese Academy of Sciences, and served as its Director from 1995 to 1999. In the 1970s, he succeeded, as a co-principal investigator, in fish cloning between different genera. In the early 1980s, he started a new research area in fish genetic engineering by producing the first batch of 2.3-3.4-fold fast-growing transgenic fish. He was elected as a member of the Third World Academy of Sciences in 1998. He served as a Vice President of the National Natural Science Foundation of China and President of China International Association for Promotion of Science and Technology. He is now a professor of Peking University School of Life Sciences and the Institute of Hydrobiology, Chinese Academy of Sciences, and the Editor General of Science China and Science Bulletin.

Open Access This article is distributed under the terms of the Creative Commons Attribution License which permits any use, distribution, and reproduction in any medium, provided the original author(s) and source are credited. 